\title{
IDENTIDADE, CONDIÇÕES DE TRABALHO E REALIZAÇÃO \\ PROFISSIONAL DO PROFESSOR QUE ATENDE O ALUNO COM DEFICIÊNCIA NO INTERIOR DA AMAZÔNIA PARAENSE
}

\author{
Lídia Alves de Oliveira ${ }^{1}$ \\ José Roberto Heloani 2
}

\begin{abstract}
RESUMO
O presente artigo é resultado de uma investigação, cuja temática trata sobre identidade, condições de trabalho e realização profissional do professor que atende o aluno com deficiência no Interior da Amazônia Paraense. A pesquisa teve como objetivo, compreender as condições de trabalho do professor que atende o aluno com deficiência, em escola regular, na Amazônia Paraense e a relação com a constituição identitária desse docente. A coleta de dados foi realizada com cinco professoras, através da técnica de Grupo Focal. Ciampa (2005), Dejours (1992), Goffmann (1979), Habermas (1990), Heloani (1994), Loureiro (2013), Fernandes (2014) e Oliveira (2016) são os principais referenciais teóricos que apoiaram a discussão e análise da empiria. Conforme o depoimento das informantes ficou claro que as mesmas se sentem realizadas tanto no plano pessoal quanto profissional, em que pese todas as intempéries impostas pelo neoliberalismo e as dificuldades naturais, políticas, econômicas e sociais amazônicas.
\end{abstract}

Palavras-chave: Identidade. Trabalho Docente. Amazônia Paraense.

IDENTITY, CONDITIONS OF WORK AND PROFESSIONAL REALIZATION OF THE TEACHER THAT SERVES THE STUDENT WITH DEFICIENCY IN THE INTERIOR OF THE

PARAENSE AMAZON

\begin{abstract}
This article is the result of an investigation, whose thematic one deals with identity, working conditions and professional fulfillment of the teacher that attends the disabled student in the interior of the Paraense Amazon. The objective of the research was to understand the working conditions of the

\footnotetext{
1 Doutora em Educação. Docente da Universidade Federal do Ooeste do Pará - UFOPA. E-

2 Professor Titular da UNICAMP - artigo referente ao seu Pós-Doutorado pelo PROCAD Parceria entre CAPES/UFOPA/UNICAMP/UNIR. E-mail: rheloani@gmail.com
} mail: lidia.ufopa@hotmail.com
\end{abstract}

Revista Exitus, Santarém/PA, Vol. 7, № 3, p. 401-426, Set/Dez 2017. 
teacher who attends the disabled student from regular school, in the Amazon Paraense and the relation with the identity constitution of this teacher. Data collection was carried out with five female teachers using the Focal Group technique. Ciampa (2005), Dejours (1992), Goffmann (1979), Habermas (1990), Heloani (1994), Loureiro (2013), Fernandes (2014) and Oliveira (2016) Theorists they supported the discussion and analysis of empiria. According to the informants' testimony, it is clear that they feel carried out both personally and professionally, in spite of all the inclemencies imposed by neoliberalism and the natural, political, economic and social difficulties of the Amazon.

Keywords: Identity. TeachingWork. Amazonia Paraense.

\section{IDENTIDAD, CONDICIONES DE TRABAJO Y REALIZACIÓN PROFESIONAL DEL PROFESOR QUE ATIENDE AL ALUMNO CON DEFICIENCIA EN EL INTERIOR DE LA AMAZONÍA PARAENSE}

\section{Resumen}

El presente artículo es el resultado de una investigación, cuya temática trata sobre identidad, condiciones de trabajo y realización profesional del profesor que atiende al alumno con deficiencia en el Interior de la Amazonía Paraense. El estudio tuvo como objetivo comprender las condiciones de trabajo del profesor del alumno con deficiencia, atendido integralmente en escuela regular, en la Amazonía Paraense y la relación con la construcción identitaria del docente. La recolección de datos se realizó con cinco profesoras a travez de la técnica de Grupo Focal. Ciampa (2005), Dejours (1992), Goffmann (1979), Habermas (1990), Heloani (1994), Loureiro (2013), Fernandes (2014) y Oliveira (2016) son las principales referencias teóricas que apoyaron la discusión y análisis de las informaciones. Conforme los testimonios se fueron exponiendo, quedó claro que se sentían realizadas tanto en el plano personal como profesional, pese a todos los obstáculos impuestos por el neoliberalismo y las dificultades naturales, políticas, económicas y sociales amazónicas.

Palabras clave: Identidad. Trabajo de docente. Amazonía paraense.

\section{INTRODUÇÃO}

Na presente pesquisa partimos da compreensão sobre a construção da identidade do professor no contexto do Mundo do Trabalho, por entendermos que mesmo um fenômeno particular não acontece dissociado 
de sua totalidade. Buscamos entender como isto repercutiu na identidade do professor que atende ao aluno com Deficiência no interior da Amazônia paraense.

Para tanto, isso nos leva a acreditar que significa assumirmos a responsabilidade de supor, conferir ou refutar a existência ou não de uma possível relação entre as transformações ocorridas no campo social, político e econômico e a construção da identidade desses professores.

Essa opção nos fez pensar em querer explicar as repercussões das Políticas Públicas no sistema escolar e no trabalho dos professores da Rede Municipal de Ensino de Santarém, mediante a instalação de um diálogo teórico reflexivo sobre as particularidades do tema (condições de trabalho e realização profissional) e temática de estudo (A construção da identidade do professor que atende ao aluno com Deficiência no Interior da Amazônia paraense).

Para entendermos as flexuosidades desse processo, acreditamos ser imprescindível que a análise do fenômeno estudado se pautasse em uma visão de totalidade, considerando-se as intervenções plausíveis para esclarecer porque este fenômeno se dá de uma forma e não de outra. Uma vez que a construção das identidades ocorre nas inter-relações constituídas no mundo do trabalho, sofrendo, desse modo, as influências das nuances dos novos arranjos neste universo.

A forma de organização do trabalho influencia diretamente tanto na construção da identidade pessoal quanto profissional. Sendo assim, também influencia, sobremaneira, na construção da identidade do profissional docente, haja vista ser impossível separar o ser pessoal do ser profissional.

O profissional docente não foge a essa regra. Pois, a consciência da sua identidade profissional é fator preponderante para o bom andamento do seu trabalho. Uma identidade bem constituída é indispensável para evolução e realização profissional, assim como para a satisfação daqueles receptores dos serviços. 
O presente trabalho teve como objetivo compreender as condições de trabalho do professor que atende o aluno com deficiência, incluído na escola regular, na Amazônia Paraense e a relação com a constituição identitária desse docente.

O professor, ao atender o aluno com deficiência na perspectiva da inclusão o faz em uma expectativa de educação integral. Isso porque este trabalha, sob princípios de educação para a humanização dos indivíduos, foca não a formalização de meros conhecimentos exigidos para o mercado de trabalho, mas com vistas à socialização e ao desenvolvimento das funções psíquicas superiores que não são adquiridas no nascimento e sim nas vivências do cotidiano.

A relevância desse estudo se dá, primeiramente, pelo fato de pesquisar a realidade concreta do grupo de professores no que concerne à sua identidade, as condições de trabalho e sua realização profissional no atendimento a alunos com Deficiência. Ele fornece dados para outras pesquisas, uma vez que a maioria das investigações realizadas, em nível nacional, traz informações sobre a realidade educacional do sul e sudeste do Brasil, regiões que apresentam condições socioeconômicas bem mais favoráveis à concretização de políticas públicas de caráter afirmativo e congêneres.

Dessa forma, investigamos quais fatores ligam o docente que atende ao aluno com Deficiência ao seu trabalho. Que tipo de ressonância simbólica traz? Qual é a sua trajetória, remuneração e reconhecimento social? Podem desenvolver outras possibilidades de trabalho? Caso afirmativo, qual o motivo pelo qual não o fazem? Investigação que se dará por meio de relatos orais realizados com os sujeitos informantes escolhidos, ou melhor, uma amostra intencional dos professores que conviveram por longos períodos com alunos com Deficiência.

Na presente pesquisa, dedicaremos esforços ao estudo do trabalho e constituição da identidade do professor que atende o aluno com Deficiência, no interior da Amazônia Paraense, buscando por meio da 
pesquisa qualitativa observar os sentidos e as interpretações que os próprios sujeitos atribuem às suas ações (LIMA, 2008).

A investigação se pautou na teoria materialista histórica dialética por esta advogar que o conhecimento se dá pela práxis, expressão da unidade indissolúvel de duas dimensões distintas no processo de conhecimento: a teoria e a ação. Supõe um determinado olhar sobre o homem, a realidade e a história, olhar dinâmico e conflitivo que surge a partir de categorias materialistas de conflito e movimento, conflitos de interesse, como, por exemplo, dilemas entre o imposto por uma lógica gerencial distante e a ação possível vivida em seu contexto.

Para tanto, consideramos de fundamental importância o resgate crítico do conhecimento já produzido sobre a problemática em jogo para se identificar diferentes perspectivas de análise e conclusões a que se chegou pelo conhecimento anterior e a indicação das premissas para o avanço do novo conhecimento. Assim poderemos fazer a nossa própria história. (FRIGOTTO, 2001; GAMBOA, 2001; HELOANI\&CAPITÃO, 2007).

Com vistas a responder aos questionamentos foi utilizada a técnica do Grupo Focal com a fala livre das informantes, que foram gravadas, transcrit as, editadas e organizadas para análise (QUEIROZ, 2008). Para análise dos dados estabelecemos conexões, mediações e contradições dos fatos que constituem a problemática da pesquisa. Assim, utilizamos a técnica de análise de conteúdo de acordo com a técnica de análise temática (BARDIN, 1979), por meio da qual se descobrem núcleos de sentido que compõem a comunicação cuja presença, ausência e frequência de aparição podem significar algo para o objetivo analítico da pesquisa, configurando-se em uma análise de significação.

Com a finalidade de manter o anonimato das informantes e a ética na pesquisa as codificamos da seguinte maneira: P (I), P (R), P (G), P (C) e P (V). É importante destacarmos que os sujeitos deste estudo são todas professoras da Educação Básica das Escolas Públicas Municipais de Santarém/Pará. 
Com base nos dados empíricos coletados e nos referenciais teóricos levantados discutimos as questões relativas à pesquisa dialogando com os sujeitos envolvidos na investigação. Priorizando a maneira como interpretam, agem e se manifestam em relação às condições de trabalho, às políticas públicas educacionais e seus efeitos no trabalho, na carreira e na construção da identidade docente e tecemos esses conteúdos a partir da nossa compreensão.

O artigo está estruturado em cinco seções, considerando a Introdução como a primeira seção: a segunda seção trata sobre a construção da identidade do professor no mundo do trabalho, a terceira discute sobre o trabalho, a identidade e a realização profissional do professor na Amazônia paraense. A quarta traz a discussão a respeito do trabalho, a formação docente e a identidade profissional na Amazônia paraense. A quinta e última seção aborda o atendimento ao deficiente numa perspectiva de educação integral em escola inclusiva no Interior da Amazônia paraense.

\section{A CONSTRUÇÃO DA IDENTIDADE DO PROFESSOR NO MUNDO DO TRABALHO}

Para analisar a identidade do professor que atende o aluno com deficiência é necessário que se leve em consideração diferentes fatores que determinaram e determinam a construção de tal identidade, tais como: aspectos históricos, sistemas econômicos, sociais, culturais, conjuntura nacional, mundo do trabalho e outros.

A análise, interpretação e discussão do tema ocorreram com base nos referenciais teóricos e coleta de dados empíricos levantados. A partir daí, discutimos a questão dialogando com os sujeitos envolvidos na pesquisa, dando prioridade à maneira como interpretam, agem e se manifestam em relação às condições de trabalho, às políticas públicas educacionais e seus efeitos no trabalho, na carreira e na construção da identidade do docente.

A perspectiva de identidade que se busca nesta investigação é a construção e consolidação no aspecto histórico dialético. Propicia um "vir-a- 
ser" constante mirando a emancipação do sujeito psíquico e social que ocorre mediante diferentes configurações e determinações da ordem social. É aquilo que na concepção de Ciampa (2005, p. 133) denomina-se de "metamorfose".

$P(R)$ : relata: no começo eu não pensei, não queria trabalhar com essa coisa de educação especial, nem sabia o que é isso: cuidar de criança com deficiência. Sempre brinquei com os meninos. Eu era meio moleca, fazia coisas de meninos. Como eu cuidava em casa de familias de crianças, dava banho, vestia, limpava a casa eu fui fazendo em uma creche e foi acontecendo. Fui cuidando, cuidando e acabei lidando. Como conhecia as pessoas lidando com gangues, fazendo o que as pessoas com mais idade não faziam. Isso ajudou. Daí fui estudar, fazer cursos e não sai mais disso. Hoje sou professora de gente que cuida de deficiente...sou professora duas vezes...Se tivesse que volt ar at rás, faria essa opção novamente.

Para Dejours (1992, p. 189), é fundamental, antes de mais nada, distinguir identidade de personalidade:

(...) uma parte importante da tradição psicanalítica confere um lugar essencial à análise da personalidade ou do caráter, isto é, às invariantes que resultam da sedimentação do drama da infância e conferem à pessoa uma estabilidade que frequentemente foi caracterizado como uma estrutura. Portanto, a personalidade, o caráter ou a estrutura não afastam os riscos da crise psíquica e da descompensação. O recurso à noção de identidade permite justamente problematizar esta tensão entre o que vem do passado que confere a estabilidade e o que na atualidade, cria o risco de desestabilizar o sujeito ou de provocar as crises de mudança. A identidade nesta perspectiva conserva sempre uma certa precariedade e jamais é definitivamente adquirida.

A identidade implica para esse autor aquilo que torna 0 indivíduo único, singular, diferente dos outros. É construída na relação com o outro, no processo de alteridade. O julgamento, neste sentido, é capital, e diz respeito ao trabalho e não ao sujeito, sobre o fazer e não o ser.

O fazer, por seu lado envia ao ter, isto é, à possessão do saber-fazer, do métier, das regras etc. O julgamento sinaliza somente em um segundo momento, para o reconhecimento do ser. Na sublimação, é ao menos o que 
sugere a clínica em psicodinâmica do trabalho, o reconhecimento da identidade passa pela mediação do trabalho. Ela jamais é diret a.

A cada vez que nessa etapa intermediária for gerada uma espécie de curto circuito, toda a economia da sublimação será arruinada. Se o reconhecimento dissesse respeito diretamente ao ser, os outros colegas interpretariam tal fato como uma situação de injustiça: reconhece-se o sujeito e não o seu trabalho, logo desconhece-se o seu sofrimento e o seu mérito, o que põe em risco de destruição toda a economia da relação sofrimento-prazer como pode ser nitidamente observado na narrativa de $P$ (G):

Eu gosto do que faço, eu gosto mesmo!

Mas gostaria de ganhar mais; dinheiro não é tudo, mas não estou satisfeita nesse nível profissional. O dinheiro é importante. Tem o reconhecimento... Gosto do que faço, mas não sei se faria novamente.

Para Dejours (1992), o processo de constituição da identidade, ao passar pelo julgamento e pelo reconhecimento do outro, implica a constituição do coletivo do trabalho. Não se deve confundir o coletivo com o grupo. O coletivo é mais que um grupo, pois o que o define é a construção de regras e ofícios que vão nortear as relações interpessoais e de trabalho.

O autor tem consciência de que é muito difícil construir o coletivo. Outro modo de nomear a construção do coletivo é a atividade deôntica: atividade de construir acordos, normas e valores que se estabilizam sob a forma de regras.

A teoria da ação comunicativa pressupõe a interação para a existência do indivíduo. Assim, a identidade que o eu experimenta é influenciada pela identidade outorgada pelo outro a esse eu.

Habermas (1990, p.22), nos ensina que:

ninguém pode edificar sua própria identidade independentemente das identificações que os outros fazem dele (...) O fundamento para a afirmação da própria identidade não é a auto-identificação tout court , mas a auto-identificação intersubjetivamente reconhecida. 
O autor detalha esse procedimento ao nos mostrar como isso ocorre no processo linguístico. As expressões eu e tu têm o sentido de autorrepresentações recíprocas. O mesmo sentido cabe às expressões Nós e Vós. A expressão Nós pode ser usada também para uma proposição que não se pressuponha uma relação complementar diante de outro grupo. Mas uma relação voltada para outros indivíduos do mesmo grupo. Também a expressão eu pode ser usada com finalidade de auto identificação, mas a autoidentificação de um eu exige o reconhecimento intersubjetivo por parte de outros Eus, que devem assumir papel comunicativo de um Tu. O reconhecimento recíproco dos membros do grupo requer relações EU-TuVós.

Assim, a identidade do eu indicaria a competência de um sujeito capaz de linguagem e ação no enfrentamento de determinadas exigências.

Habermas (1990), desse modo, também nos traz a ideia da socialização da identidade, reafirmando que a identidade é gerada pela socialização em um processo em que o sujeito, pela apropriação de universos simbólicos, acaba por integrar-se em determinado sistema social. Posteriormente, essa mesma identidade é garantida e se desenvolve pelo aumento de independência do indivíduo em relação a esses sistemas sociais, o que ocorre em um processo de individualização.

Passemos a palavra ao próprio Habermas (1990, p.70):

(...) a identidade do Eu pode se confirmar na capacidade que tem o adulto de construir, em situações conflitivas, novas identidades, harmonizando-as com as identidades anteriores agora superadas, com a finalidade de organizar - numa biografia peculiar - a si mesmo e às próprias interações, sob a direção de princípios e modos de procedimento universais.

Vale lembrar que para Berger e Luckmann (1991), os papéis representam a ordem institucional, ou seja, o papel seria uma atividade padronizada previamente também pela identidade coletiva, que não depende da vontade individual e surge como imagens preestabelecidas, rotulações que aderem à identidade individual, em uma tentativa de 
manutenção de crenças sociais que garantem certa continuidade e cognoscibilidade da identidade coletiva.

Ciampa (2005) define identidade-mito no momento em que o sujeito não consegue atingir a condição de "ser-para-si" mediante a não superação de contradições no sentido dialético do termo. A complexidade da constituição identitária é simplificada e, até mesmo, naturalizada, como verdadeiro ato de fé e paixão, como pudemos perceber na narrativa de $P$ (I):

Eu tenho a questão da educação, do atendimento ao aluno deficiente no sangue. Tá no meu sangue. Eu sempre tive isso. É um sonho de infância que eu consegui realizar.

Aqui jaz a professora "I", quando eu morrer... Quero que escrevam no meu túmulo!

Não saberia fazer outra coisa. Nasci pra isso. Amo tudo isso. Tá no sangue!

Em nosso entender, há forte semelhança entre o que Habermas chama de identidade do Eu e aquilo que Ciampa denomina de condição de "ser-para-si".

De acordo com Habermas (1983, p. 25),

(...) a identidade de papel é substituída pela identidade do Eu, na exata medida em que o Eu generaliza a capacidade de superar uma velha identidade e aprende a resolver as crises de identidade reconquistando a nível mais alto o equilíbrio perdido entre si e a realidade social modificada. Pode dizer "Eu" de si mesma.

Enquanto na abordagem de Ciampa, a questão identitária do "serpara-si" é a busca da autonomização, sem a ingenuidade da inexistência de determinações exógenas na procura da "unidade da subjetividade e da objetividade, que faz do agir uma atividade finalizadora relacionando desejo e finalidade, pela prática transformadora de si e do mundo". (2005, p.146).

Aliás, esse autor nos ensina que identidade é metamorfose, ou seja, está em constante transformação. O que nos remete à ideia de Habermas de que a identidade em nível pós-convencional seria aquela em que o 
desenvolvimento da consciência moral supere o estágio convencional, rompendo os limites da identidade de papel, à medida que adquire a capacidade de julgar, definindo princípios e valores morais, cuja validade independe de autoridade exterior. Dessa forma, a identidade vai sendo constituída mediante reiteradas identificações do próprio indivíduo em relação a si mesmo e ao meio social.

A Identidade pessoal e a Identidade profissional se mescla, conforme visualizamos na fala de $\mathrm{P}(\mathrm{V})$ :

Quando chega sábado, ou vai chegando o sábado e o domingo parece que o dia não passa... o final de semana eu fico preocupada, fico triste, meio preocupada, pois sei que não vou pra escola. Sou feliz, sei que gosto do que faço, não conseguiria fazer outra coisa!

Quando faltei, uma vez, porque fui fazer um exame preventivo, chegou um pai e disse que sentiu a minha falta. Daí eu mandei uma substituta, minha filha, e me senti mal, meio estranho, ainda bem... Sou feliz, amo isso e faria novamente.

Goffman (1979) define a identidade social e a identidade pessoal de maneira em que a primeira consiste nos papéis que o indivíduo desempenha suas representações no cenário em que se apresenta, enquanto a segunda é o que torna a pessoa única, com suas características subjetivas, intrínsecas. Na construção da identidade pessoal de um indivíduo são usados aspectos da identidade social.

\footnotetext{
Normas relativas à identidade pessoal, entretanto, pertencem não a esferas de combinações permissíveis de fatos sociais mas ao tipo de controle de informação que 0 indivíduo pode exercer com propriedade. Para uma pessoa, ter tido o que se chama de um passado sombrio é uma questão relativa à sua identidade social; a maneira pela qual ele manipula a informação sobre esse passado é uma questão de identificação pessoal (GOFFMAN, 1963, p.74).
}

Parece-nos, portanto, que é difícil dissociar a identidade pessoal da identidade social e profissional, uma vez que ambas fazem parte da mesma pessoa. Identidade é unidade entre objetividade e subjetividade, como nos ensina Ciampa (2005) e é nessa unidade que se dá a metamorfose, 
transformação constante. A narrativa que se segue é elucidativa no que concerne a esse movimento:

$P(C)$ relata: comecei no comércio, mas não tinha jeito pra isso. Jeito nenhum, embora minha família toda seja de comerciantes, inclusive meu marido. Não sabia cobrar, chegava no trabalho certinho, na hora certa, cedo, mas não dava, não sabia trabalhar no comercio, não sabia os traquejos do comércio. Comecei a pensar em fazer outra coisa, em ser professora. Às vezes eu chegava em casa toda esfumaçada, pois eu era professora, mas além de dar aula eu ainda precisava fazer a merenda, arrumar e limpar a sala etc. Um dia o meu marido perguntou depois de me dar um cheiro e sentir a fumaça impregnada no meu corpo inteiro. Você é professora ou merendeira?

A narrativa da informante mostra como a vida pessoal se mistura à social e profissional, principalmente quando ela fala que resolveu mudar de profissão e quando mostra, também, como chegou na Educação Especial.

Lidar com deficientes: eu tinha o magistério e poucas pessoas tinham magistério. Fui fazer curso e fui indo...fui indo e comecei a lidar com isso. O primeiro aluno foi um cego, como eu tinha jeito, fui fazendo cursos e fui trabalhando com isso.

Eu podia trabalhar no comercio, mas não deu certo, não! Se fosse pra EU escolher, hoje, escolheria novamente isso. Hoje eu gosto.

A pessoa fica presa em uma espiral da qual não consegue mais se desligar. A ligação dos indivíduos é produzida não por uma coerção física, mas por uma dependência psíquica que se apoia sobre os mesmos processos que os laços amorosos, ou seja, projeção, introjeção, idealização, o prazer e a angústia. (GAULEJAC, 2007, HELOANI, 1994). Como se observa, são situações de trabalho onde o docente fica amarrado, como já dissemos, a uma lógica que envolve o campo psicológico e o envolvimento subjetivo, fundado em expectativas de reconhecimento.

Entendemos que a construção das identidades se dá dentro de um contexto concreto e, portanto, sofre influências constantes das reformas estatais, das políticas públicas e da legislação delas decorrentes, assim como, dos novos arranjos no mundo trabalho. As identidades são 
construções sócio-históricas e culturais e por isso, não ocorrem de forma isolada. Parte e todo se completam na unidade. Tudo se relaciona se complementa e se transforma em razão da totalidade.

\section{O TRABALHO, A IDENTIDADE E A REALIZAÇÃO PROFISSIONAL DO PROFESSOR NA AMAZÔNIA PARAENSE}

Nesta seção, continuamos analisando e interpretando com base nos dados empíricos coletados e nos referenciais teóricos levantados, de posse desses fundamentos discutimos a questão dialogando com os sujeitos envolvidos na pesquisa, dando prioridade à maneira como interpretam, agem e se manifestam em relação às condições de trabalho, às políticas públicas educacionais e seus efeitos no trabalho, na carreira e na construção da identidade do docente.

Do ponto de vista de sua composição cultural, a população amazônica é caracterizada por uma rica sociobiodiversidade. Existem na região milhares de indígenas, constituindo várias etnias diferentes em pleno domínio e uso de suas línguas e culturas específicas. Além disso, culturas caboclas, vividas por grupos ribeirinhos que habitam o interior, às margens de rios, lagos e igarapés constituem também modos de vida amazônidas representando experiências e conhecimentos sobre formas de coexistência e utilização do meio local.

Quanto a esta questão, P (I) argumenta:

é notório, com certeza que o fato de estarmos na Amazônia é um fator de maior desafio para a educação escolar, porque eles las autoridades) veem a Amazônia com pensamento pejorativo, Amazônia é sinônimo de índio e que por isso não precisa de conhecimento, então muitas coisas que poderiam estar nos subsidiando em prol da educação acontece mais no sul, sudeste, enquanto para nós, Norte e Nordeste somos ainda discriminados, principalmente tratando-se da Amazônia, única coisa que eles veem claramente é a nossa florest a, que todo mundo tem os olhos grandes em cima da nossa floresta, mas quando tange a bens em prol da educação e da saúde nós sofremos, eu tenho até assim algo de descriminação mesmo. 
P (I) continua sua narrativa dizendo: como profissional da educação eu me sinto privilegiada por est ar na Amazônia, porque é uma região riquíssima, trabalhando em cima do que nós temos de economia, infelizmente ainda não fica no nosso município, vai tudo para Belém, mas se ficasse no nosso município com cert eza nós teríam os condições melhores, mais impost os para est ar fazendo invest iment os maiores na nossa cidade, então, como professora da Amazônia eu me sinto privilegiada.

Igualmente, estas questões sociais e culturais colocam - tanto para os gestores, técnicos da educação e os professores, quanto para outros segmentos sociais comprometidos com a produção de uma vida melhor dois grandes desafios: o primeiro, diz respeito à extensão da escola para cada criança e jovem, extinguindo a exclusão educacional e o segundo, à produção de uma educação competente, capaz de elaborar um discurso, uma ética e um conjunto de conhecimentos e atitudes, direcionados ao respeito ao multiculturalismo e à prática da conservação ambiental na região (OLIVEIRA, 2016).

Nessa mesma direção, $P(R)$ assegura: bem, como professora que pratico esse serviço na Amazônia, eu me sinto muito bem, porque eu sei que o ensino que eles estão tendo aqui na Amazônia vai servir para a vida deles. E continua argumentando: $O$ professor que não acredita que vai melhorar ainda mais através do ensino, então ele não está acreditando no que está fazendo, ele tem que acreditar no que ele traz para oferecer à população e nessa vont ade que o povo tem para aprender.

A Amazônia ela é rica não somente na fauna, na flora e tudo que ela tem, mas também no povo que vive aqui, porque o povo sabe o que quer.

A gente observa nas práticas da docência que ser professor na Amazônia é nos ident ificarmos, fazer com que a educação est eja viva, ela está em nós, faz parte de cada um de nós, então aqui na Amazônia tudo se aproveita através do que acontece nesse meio, com esse povo, com essa gente que gost a de estudar, de aprender. É uma educação concreta, cativante, que me realiza com certeza. Aqui quem estar no sangue, na docência do profissional da Amazônia se identifica nessa identidade. O professor traz à tona uma realidade que ele vivencia na sala de aula. A gente vivencia esses profissionais que se apropriam desses saberes que são de regiões diferentes e faz ali um encontro de realidades para que o aluno busque aquilo que é 
importante, aquilo que faz parte do convívio dele. Ele cont ext ualiza os saberes do País.

Embora a Amazônia seja uma região reconhecida por suas especificidades, no que concerne à sua natureza ímpar de verdes e águas, às longas distâncias a percorrer, às chuvas sazonais e outras mais, não tem havido até hoje, programas federais especificamente destinados a ela, com recursos e características que lhes sejam próprios (LOUREIRO, 2007).

As expectativas positivas das professoras participantes da pesquisa as levam a mostrarem-se muito firmes em seus propósitos - fazer sempre o melhor para seus alunos e trabalhar em prol do bem comum, e da melhoria de sua vida, assim como de seus familiares e da comunidade. Diante do exposto $P(G)$ narra:

ser professor na Amazônia é muito difícil. Já pensou você atravessar o Tapajós ou o Amazonas para você dar uma aula lá numa comunidade? É muito difícil. Ser professor na Amazônia é vencer os desafios da Amazônia, que não são fáceis e não são poucos. Desafio do financeiro, das condições físicas, ambientais, políticas, culturais, sociais, sem investimentos, lidar com famílias desestruturadas, com pessoas que não valorizam a educação escolar.

Os desafios que persistem, hoje, na região amazônica são de várias ordens e são velhos conhecidos, haja vista que as "Políticas nacionais supostamente igualitárias, apenas perpetuam as desigualdades regionais" (LOUREIRO, 2013, p. 170). Quando se trata de educação, essas políticas não favorecem a região e ainda concorrem para aumentar consideravelmente as desigualdades regionais.

\begin{abstract}
Vale lembrar que em termos de Amazônia a tônica ainda continua sendo a de projetos que prometem o desenvolvimento de suas regiões, sem que isso tenha representado profundas mudanças no modo de conceber o seu efetivo desenvolvimento, uma vez que a escolha de projetos para desenvolver a região mais rica em biodiversidade do mundo, ainda carrega a marca da exclusão (ARAÚJO, 2013, p. 47).
\end{abstract}

Diante dos inúmeros projetos implantados na região, percebemos o agravamento das desigualdades, a começar pelas condições materiais das 
redes escolares até a qualidade da educação. Em que pese à modernização e a individualização forjadas nas entranhas do neoliberalismo, a Amazônia continua espoliada em seus direitos básicos, como: saúde, assistência, segurança e educação de qualidade (OLIVEIRA, 2016). Desta forma, não promove um atendimento que visualize suas especificidades. Nessa mesma direção P (C) faz as seguintes colocações:

Ser professor na Amazônia é um desafio, nossa profissão é um desafio. Como falei para você nosso público é o aluno, a gente atende a necessidade de sempre est armos ali atent o pelo fat o de a família não assumir esse compromisso com a criança de não está ali preocupada de orient ar como deve e deixa esse compromisso com o professor de orientar, porque acha que é só responsabilidade do professor por aquela criança que tem aquela deficiência. É um desafio porque é uma das coisas que temos que falar para essa familia a importância daquela criança também, a importância do aluno como pessoa, como ser humano que tem necessidade de aprender, não aprende tudo como o outro "normal" aprende, mas ele precisa, ele precisa ler uma receita, ele precisa ir ao centro e pegar um ônibus, fazer uma compra, precisa pagar cont as, resolver suas coisas do dia-a-dia, saber fazer um orçamento de quanto ele gasta num mês ou arranjar um trabalho, se formar em uma profissão. O desafio é sempre estar valorizando a criança, que ele é importante para continuar. A minha mãe sempre falava essas coisas boas, de ver a gente formada, isso ali era "adubando" as nossas vidas, falando coisas boas a nosso respeito. Então eu tento que fazer com que essa criança se sinta bem, se sinta valorizada.

Nas políticas neoliberais não existe espaço para atender especificidades regionais, pois quem não se adéqua aos ditames impostos por esse modelo, logo estará fora de qualquer possibilidade de inserção, visto que a exclusão é a marca por excelência deste modelo.

Levando em conta que a profissão docente amazônida se constrói em meio a dificuldades regionais, quando se trata de professor que atende ao aluno com deficiência se tornam ainda maiores. Dependendo do nível da deficiência essas dificuldades se constituem em desafios quase insuperáveis.

Os esforços de superação que os professores empreendem para se adequar às adversidades impostas pelas condições naturais da Amazônia e outras criadas por questões sociopolíticas e econômicas na/da região é uma 
questão que requer profunda reflexão (OLIVEIRA, 2016). É importante observarmos como as experiências vividas modificam a análise de cada um do mesmo contexto. Isso faz uma diferença enorme ao avaliar as condições de acesso e trabalho na Amazônia.

Para compreendermos a constituição dos sujeitos amazônicos se faz necessário correlacionarmos as suas condições concretas de possibilidades à história nacional, ao modo como a Amazônia foi explorada para a sustentação de um capitalismo dependente que colocou o Brasil na condição de economia emergente (OLIVEIRA, 2016). Essas condições, certamente estarão presentes no mundo do trabalho e influenciarão sobremaneira tanto na formação docente, quanto na construção da identidade profissional.

\section{O TRABALHO, A FORMAÇÃO DOCENTE E A IDENTIDADE PROFISSIONAL NA} AMAZÔNIA PARAENSE

Ao tratarmos de trabalho docente, necessariamente, precisamos recorrer à questão da formação profissional, considerando que um bom exercício do magistério está diretamente vinculado a uma formação de qualidade que dê acesso a este profissional aos conhecimentos produzidos de maneira histórica e socialmente reconhecidos.

\footnotetext{
O ato educativo pressupõe o homem diante de outro homem, fundando-se numa relação mediada pelas apropriações e objetivações que os constituem, de sorte que não existe ação educativa que não seja permeada pela subjetividade dos envolvidos. Assim, ao promover apropriações qualitativamente superiores, não cotidianas, ao transmitir os conhecimentos historicamente sistematizados, é que a educação escolar assume sua principal função na formação e transformação da subjetividade tanto de professores quanto de alunos (MARTINS, 2014, p. 109).
}

A educação escolar não tem conseguido a transformação da subjetividade na contra direção dos ditames impostos pelo neoliberalismo. $O$ que temos visto, ao longo dos anos, é a escola perpetuando o modelo sociopolítico e econômico vigente, mesmo na Amazônia. 
(...). Neste processo, as críticas e, ao mesmo tempo, as soluções foram depositadas nos professores como se estes, individual e isoladamente, fossem capazes de garantir uma educação melhor. Entretanto, numa sociedade desigual, o que implica variações significativas no acesso às condições objetivas, a escola mantém sua característica excludente - principalmente no que se refere à apreensão do conhecimento - e isso interfere diretamente no trabalho docente que, por sua vez, se reflete na sala de aula (FERNANDES, 2014, p. 111).

Tanto a formação de professores quanto a educação vem seguindo os interesses do capital e em grande medida tem restringido o processo de aprendizagem e de formação aos valores e padrões societários do individualismo, da competitividade, do mérito e do status pessoal na estrutura social, subordinando e confinando o papel da escola à lógica das relações de mercado como espelho do sucesso, colocando de lado, a responsabilidade com o ensino-aprendizagem na perspectiva da formação crítico-reflexiva dos sujeitos. Quanto a esta questão $P(G)$ discorre:

Formação, vontade a gente tem bast ante, mas a região não facilita nossa vida em relação a acesso, não tem. Graças a Deus a UFOPA está começando a facilitar bem devagarzinho. A busca está sendo muito grande. Se nós tivéssemos a oport unidade de quem mora em outras regiões com mais acesso a informações. Quando se trat a de formação de professor ela é bem adversa e quando tem, tudo é muito caro. E quando tem, não é de qualidade, as pessoas estão buscando só por questão de certificação. Aí não sou muito de investir naquilo que não é de qualidade, eu quero qualidade, não quero só certificado, certificado é bom também, financeiramente é bom, mas profissionalmente não, porque tu tens certificação, mas não tem base para aquilo ali.

Esse modelo de formação tem deixado o professor entregue a seus próprios esforços, cabendo a ele a iniciativa e a vontade de continuar a estudar sempre. É evidente que se trata de uma lógica perversa que retira a responsabilidade da formação do âmbito do Estado e repassa aos indivíduos (FERNANDES, 2014).

A contribuição da Universidade Federal do Oeste do Pará tem sido de extrema relevância na formação de professores para a região Amazônica. Mas, a falta de professores capacitados para atender as demandas tanto da educação básica, quanto da educação superior ainda é uma realidade 
no país e quando tratamos da Amazônia esta situação se torna mais grave por todas as questões já colocadas (OLIVEIRA, 2016).

Quando se trata de políticas educacionais a serem construídas para o campo na Amazônia estas devem assumir a responsabilidade com a formação desse novo sujeito crítico, a partir de seu lugar, ou seja, pensar e efetivar políticas para a educação do campo a partir das peculiaridades amazônicas e com a participação ativa do conjunto de seus sujeitos, não de forma isolada, mas como um espaço em inter-relação com outros espaços sociopolíticos e culturais, em nível regional, nacional e global, considerando os conflitos existentes e fortalecendo essa cultura política participativa e protagonista na Amazônia e na sociedade.

$\mathrm{Na}$ articulação entre o conceito de identidade-metamorfose e identidade-mito buscamos a compreensão da participação da dimensão subjetiva na interpretação do mundo. Assim, por meio do pensamento habermasiano, que categoriza o agir instrumental e o agir comunicativo, tendemos a interpretar os fatos sociais como se fossem fenômenos naturais. Tal atitude nos afasta de nosso papel de construtores da realidade e exclui o caráter histórico de nosso "existir". Desta forma, quando discutimos Educação Inclusiva procuramos não cometer esse erro.

No atendimento ao aluno com deficiência é imprescindível antes de qualquer atitude, termos a compreensão de que este indivíduo é um ser histórico e, portanto, multideterminado com características próprias, diversas e específicas e que merece ser atendido em sua integralidade.

\section{O ATENDIMENTO AO DEFICIENTE, NA PERSPECTIVA DE EDUCAÇÃO INTEGRAL EM ESCOLA INCLUSIVA NO INTERIOR DA AMAZÔNIA PARAENSE}

Compreendemos que o professor, ao atender ao aluno com deficiência na perspectiva da inclusão, o faz em uma expectativa de educação integral. Isso porque este trabalha sob princípios de educação para a humanização dos indivíduos, focando não a formalização de meros 
conhecimentos exigidos para o mercado de trabalho, todavia com vistas à socialização e ao desenvolvimento das funções psíquicas superiores que não são adquiridas no nascimento, mas nas vivências do cotidiano. Corroboramos, desta maneira, com as ideias de Marx (1962), quando preconiza que o ser humano se apropria das qualidades humanas ao se apropriar da cultura social e historicamente construídas.

Para ele:

Todas as suas relações com o mundo - ver, ouvir, cheirar, saborear, pensar, observar, sentir, desejar, agir, amar - em suma, todos os órgãos da sua individualidade, como órgãos que são de forma diretamente comunal, são, em sua ação objetiva (sua ação com relação ao objeto) a apropriação desse objeto, a apropriação da realidade humana (MARX, 1962, p.126).

A inclusão realizada no intuito de socialização e desenvolvimento de qualidades humanas como autocontrole, atenção, memória, motivação, entre outras funções psíquicas superiores, transcende o papel da Educação Escolar desenvolvida pelo Estado Moderno de instrumentalizar indivíduos para o trabalho. Já que, quase em sua totalidade, a escola pouco vem desenvolvendo estas funções psíquicas, mas operando na formação de indivíduos mais egocêntricos e dependentes do sistema para sobreviver.

Nas primeiras três décadas do século XX, encontramos no Brasil, propostas expressivas favoráveis à Educação Integral. Anarquistas, católicos, integralistas e educadores da estatura de Anísio Teixeira, defendiam e procuravam implantar instituições educacionais em que essa concepção fosse vivenciada e aplicada. No entanto, como se pode notar, eram propostas advindas de concepções ideológicas, metodológicas e epistemológicas bem distintas; às vezes, até, inconciliáveis, no conteúdo e na forma.

O Movimento Integralista advogava a Educação Integral, com base nos escritos de Plínio Salgado- seu líder - mas também se rendiam aos apelos de juristas como Godofredo da Silva Telles, que, por certo tempo, foi simpático a esse movimento nacionalista, abandonando-o rapidamente. 


\section{Para os adeptos dessa concepção, os fundamentos da Educação Integral} eram, mormente, o nacionalismo, o patriotismo e a disciplina em seus múltiplos aspectos.

Em sentido oposto, os anarquistas - inspirados principalmente em Bakunin (2003), pleiteiam a igualdade, a autonomia e a liberdade humana. Somente uma educação plena, ou melhor, integral poderia possibilitar a construção de um novo tipo de sociedade, em uma clara opção política emancipadora. Bakunin (2003), não somente considerava forçoso diminuir a distância entre a educação fornecida aos filhos dos trabalhadores e aquela desfrutada pela classe burguesa, como explicitava o seu conceito de emancipação via educação:

Toda educação racional nada mais é, no fundo, que a imolação progressiva da autoridade em proveito da liberdade, onde esta educação tem como objetivo final formar homens livres, cheios de respeito e de amor pela liberdade alheia. Assim o primeiro dia da vida escolar deve ser o de maior autoridade e de uma ausência quase total de liberdade; mas seu último dia deve ser o de maior liberdade e de abolição absoluta de qualquer vestígio do princípio animal ou divino de autoridade (BAKUNIN, 2003, p. 47).

A educação como um processo de humanização não ocorre quando o foco está direcionado para um tipo de atividade formal como tem desenvolvido a escola, mas quando apresenta aos seus alunos os conhecimentos mais elaborados construídos pela humanidade. Isso porque, como afirma Leontiev (1978, p.272):

As aquisições do desenvolvimento histórico das aptidões humanas não são simplesmente dadas aos homens nos fenômenos objetivos da cultura material e espiritual que os encarnam, mas estão aí apenas postas. Para se apropriar destes resultados, para fazer deles as suas aptidões, "os órgãos da sua individualidade", a criança, o ser humano, deve entrar em relação com os fenômenos do mundo circundante através doutros homens, isto é, num processo de comunicação com eles. Assim, a criança aprende a atividade adequada. Pela sua função, este processo é, portanto, um processo de educação. 
Tal como Leontiev (1978), concebemos a inclusão das pessoas com deficiência no espaço escolar como um complexo, mas necessário, processo semiótico, sem o qual a aprendizagem não se faz ou fica debilitada.Em uma perspectiva inclusiva de educação escolar o aluno com deficiência acaba permanecendo mais de seis a oito horas no ambiente escolar, pois, em um período do dia ele é atendido na sala de aula comum e, em outro período, ele é atendido na sala de recursos multifuncionais, onde são realizadas outras atividades para melhor desenvolver seu cérebro e o convívio no núcleo escolar e social.

Sobre a forma como a escola desenvolve suas atividades, Cavaliere (2002, p.259) infere que:

a formalização da educação por meio de uma instituição - a escola - não deve significar que o fenômeno que dentro dela ocorra, seja qualitativamente diferente do fenômeno global de vida/experiência/aprendizagem que caracteriza a própria condição humana.

A autora, com base nas ideias de Dewey, amplia a concepção de educação escolar tradicional que se reproduz ainda no interior da escola. Contudo, o discurso acaba se esvaziando quando a realidade não apresenta condições necessárias para que essa concepção seja efetivada na prática.

Considerando as narrativas das informantes deste estudo, o atendimento feito ao aluno com deficiência nas escolas inclusivas de Santarém procura atender os princípios norteadores de uma Educação Integral, onde o aluno aprende com e para a vida do cotidiano.

\section{CONSIDERAÇÕES FINAIS}

A investigação mostrou resultados mais amplos alcançados a partir da literatura já produzida e outros percebidos como mais específicos, pelo fato 
de estarem mais inteiramente relacionados ao objeto de estudo, o que traremos nessas considerações finais.

Ao analisarmos a construção da identidade do professor através da psicodinâmica cotidiana no âmbito da organização do trabalho na escola pública municipal de Santarém, observamos que este profissional atende ao aluno com Deficiência numa realidade escolar imprópria a um serviço de qualidade pelas próprias características típicas da região no interior da Amazônia paraense. Ao mesmo tempo, pelas dificuldades e limitações impostas, como a falta de infraestrutura, de recursos financeiros, de formação adequada ao atendimento desse público, de vontade política e de qualquer tipo de apoio e incentivo.

As análises realizadas ao longo da investigação mostraram que não dá para estudar um fenômeno mesmo individual como a identidade e explorar os meandros do seu processo de construção, sem conhecer o contexto a partir do qual este processo se estabelece em dada realidade. Mostramos ainda as nuances dos novos arranjos neste universo em decorrência de políticas públicas forjadas nas entranhas do sistema neoliberal e como estes vão influenciar diretamente as atividades na escola, suas consequências para a construção da identidade e do trabalho do professor.

A forma de organização do trabalho influencia diretamente tanto na construção da identidade pessoal quanto profissional. Sendo assim, também influencia sobremaneira na construção da identidade do profissional docente, haja vista ser impossível separar o ser pessoal do ser profissional.

O profissional docente não foge a essa regra. Pois, a consciência da sua identidade profissional é fator preponderante para o bom andamento do seu trabalho. Uma identidade bem constituída é indispensável para evolução e realização profissional, assim como para a satisfação daqueles receptores dos serviços.

Pelas colocações das informantes fica evidente que as mesmas trabalham na perspectiva do exercício pleno da cidadania e na busca por 
igualdade de direitos e deveres. Mostram que são profundas conhecedoras das peculiaridades regionais. Elas trazem para o contexto da sala de aula outras realidades que se adicionam ampliando não só os conhecimentos de seus alunos, mas também seus horizontes, criando assim novas perspectivas de vida.

Tomando como base as narrativas das informantes e os estudos de Habermas (1990) poderíamos dizer que as mesmas se mostram como um exemplo de identidade bem sucedida do "Eu". Mesmo passando por todos os percalços impostos pelas condições econômicas precárias e várias adversidades naturais da Amazônia, assim como, pouquíssimas condições materiais disponíveis - elas não desistem e pelo contrário, ao longo de suas vidas/carreiras persistem firmes e a cada dia se sentindo realizadas profissionalmente.

Entendemos que, mesmo diante de percalços e dificuldades enfrentadas pelas professoras no Interior da Amazônia paraense, no atendimento ao aluno com deficiência, as mesmas conseguem superar até mesmo as expectativas de um atendimento preconizado pelas políticas de Educação em tempo Integral.

\section{REFERÊNCIAS}

ARAÚJO, F. L. G. M. P. de. Notas introdutórias: a educação na Amazônia em números. In: DIREITO HUMANO à educação na Amazônia: uma questão de justiça. Flávia L. G. M. P. de Araújo (org.). Dossiê da sociedade paraense de defesa dos direitos humanos. Belém/PA. 2013.

BAKUNIN, M. A instrução integral. São Paulo: Imaginário, 2003.

BARDIN, L. Análise de conteúdo. Lisboa: Edições 70, 1979.

BERGER, P. I.; LUCKMANN, T. A construção social da realidade. 9ed. Petrópolis: Vozes, 1991.

CA VAlieRe, A. M. V. Educ. Soc., Campinas, vol. 23, n. 81, p. 247-270, dez. 2002. Disponível em <http://www.cedes.unicamp.br>

CIAMPA, A. da C. A Estória do Severino e a História da Severina: um ensaio de Psicologia Social. 10 ${ }^{a}$ reimp. da $1^{a}$ ed. de 1987. São Paulo: Brasiliense, 2005. 
DEJOURS, C. A loucura do trabalho: estudo da psicopatologia do trabalho. $5^{\text {a }}$ ed. São Paulo: Cortez - Oboré, 1992.

FERNANDES, M. J. S. Formação de professores no Brasil: algumas reflexões a partir do trabalho docente. In: MILLER, Stela; BARBOSA, Maria Valéria; MENDONÇA, Sueli Guadelupe de Lima (Orgs.). Educação e Humanização: as perspectivas da teoria histórico-cultural. Jundiaí/SP: Paco Editorial, 2014.

FRIGOTTO, G. O enfoque da dialética materialista histórica na pesquisa educacional. In: FAZENDA, I. (Org.). Metodologia da pesquisa educacional, SP, Cortez, 2001, pp. 69-90.

GAMBOA, S.A.S. A dialética na pesquisa em educação: elementos de contexto. In: FAZENDA, I. (Org.). Metodologia da pesquisa educacional, SP, Cortez, 2001, pp. 91-115.

GAULEJAC, V. de.Gestão como doença social: ideologia, poder gerencialista e fragmentação social. A parecida, SP: Ideias \& Letras, 2007.

GOFFMANN, E. Estigma: notas sobre a manipulação da identidade deteriorada. Rio de Janeiro: Zahar, 1979.

HABERMAS, J. Para a reconstrução do materialismo histórico. SP: Brasiliense, 1990.

HELOANI, R. Organização do trabalho e administração: uma visão multidisciplinar. São Paulo: Cortez. 1994.

HELOANI, R.; CAPITÃO, C. Formulações gerais sobre o objeto de pesquisa em psicologia: um estudo de caso. In: MATIAS, C. M. M.; ABID, J. A. D. (Orgs.). Sociedade em transformação: estudo das relações entre trabalho, saúde e subjetividade. Londrina: Eduel, 2007. Pp. 17-35.

LOUREIRO, V. R. Educação e Sociedade na Amazônia em mais de meio século. Revista Cocar/UEP. Pará, V. 01, n 1, jan/jun 2007.

LOUREIRO, V. R. Educação básica como direito humano e capital social: o caso amazônico como retrato da desigualdade. In: Flávia L. G. Marçal Pantoja de Araújo (Org.). Dossiê da sociedade paraense de defesa dos direitos humanos. Belém/PA. 2013.

LEONTIEV, A. N. O desenvolvimento do psiquismo. Tradução de Manuel Dias Duarte. Lisboa: Livros Horizonte, 1978. LIMA, L. C. A escola como organização educativa. 2.ed. São Paulo: Cortez, 2003.

MARTINS, L. M. A constituição histórico-social da subjetividade humana: contribuições para a formação de professores. In: MILLER, Stela; BARBOSA, Maria Valéria; MENDONÇA, Sueli Guadelupe de Lima (Orgs.). Educação e Humanização: as perspectivas da teoria histórico-cultural. Jundiaí/SP: Paco Editorial, 2014. 
MARX, K. Manuscritos econômicos e filosóficos. In: FROMM, E. O conceito marxista de homem. Tradução de T. B. Bottomore. Rio de Janeiro, RJ: Civilização Brasileira, 1962. p. 91-179.

OLIVEIRA, L. A. de. A construção da identidade do docente que atende ao aluno com deficiência intelectual incluído na classe comum da escola regular no interior da Amazônia paraense. Tese (Doutorado). Campinas, SP, 2016.

QUEIROZ, M.I.P. Histórias de vida e depoimentos pessoais. In: LUCENA, C.T.; CAMPOS, M.C.S.S.; DEMARTINI, Z. B. (Orgs.). Pesquisa e ciências sociais: olhares de Maria Isaura Pereira de Queiroz. Textos CERU. Série $2-n^{\circ} 10$. SP: CERU/ Humanitas, 2008.

Recebido em: Fevereiro de 2017 Aceito em: Julho de 2017 